\title{
Towards a global list of accepted species II. Consequences of inadequate taxonomic list governance
}

\author{
Scott A. Thomson ${ }^{1} \cdot$ Kevin Thiele $^{2,3}$ (1) $\cdot$ Stijn Conix ${ }^{4}\left([) \cdot\right.$ Les Christidis $^{5} \cdot$ Mark John Costello $^{6,7} \cdot$ Donald Hobern $^{8}$ (1) \\ Svetlana Nikolaeva9,10,11 $\cdot$ Richard L. Pyle ${ }^{11,12}$ - Peter Paul van Dijk ${ }^{13}$ (1) $\cdot$ Haylee Weaver ${ }^{14} \cdot$ Frank E. Zachos $^{15,16,17}$. \\ Zhi-Qiang Zhang ${ }^{18,19}$ (i) Stephen T. Garnett ${ }^{20}$ (i)
}

Received: 17 June 2021 / Accepted: 30 August 2021 / Published online: 14 October 2021

(c) Gesellschaft für Biologische Systematik 2021

\begin{abstract}
Species lists are widely used in legislation and regulation to manage and conserve biodiversity. In this paper, we explore the issues caused by the lack of an adequately governed and universally accepted list of the world's species. These include lack of quality control, duplicated effort, conflicts of interest, lack of currency, and confusion in the scientific use of taxonomic information. If species lists are to fulfill their role efficiently, then the governance systems underlying their creation must keep pace. Fortunately, modernization of species list governance is now possible as a result of advances in biodiversity informatics and two decades of experience working to create the backbone of a global species list.
\end{abstract}

Keywords Nomenclature $\cdot$ Taxonomy $\cdot$ Medicine $\cdot$ Pest management $\cdot$ Global species lists

This article is part of the Special Issue and Topical Collection Towards a global list of accepted species

Scott A. Thomson

scott.thomson321@gmail.com

Stijn Conix

stijn.conix@kuleuven.be

Les Christidis

les.christidis@gmail.com

Donald Hobern

donald.hobern@sp2000.org

Richard L. Pyle

deepreef@bishopmuseum.org

Peter Paul van Dijk

ppvandijk@rewild.org

Haylee Weaver

Haylee.Weaver@awe.gov.au

Frank E. Zachos

frank.zachos@nhm-wien.ac.at

Stephen T. Garnett

stephen.garnett@cdu.edu.au

1 Centro de Estudos Dos Quelônios da Amazônia - CEQUA, Manaus, Amazonas, Brazil

2 Australian Academy of Science, Canberra, ACT, Australia

3 School of Biological Sciences, University of Western Australia, Perth, Australia

4 Centre for Logic and Philosophy of Science, KU Leuven, Leuven, Belgium

5 Southern Cross University, Coffs Harbour, NSW, Australia
6 Faculty of Biosciences and Aquaculture, Nord University, Bodo, Norway

7 School of Environment, University of Auckland, Auckland, New Zealand

8 Canberra 2000, Australia

9 Natural History Museum, London, UK

10 Kazan Federal University, Kazan, Russia

11 Borissiak Paleontological Institute, Moscow, Russia

12 Bernice Pauahi Bishop Museum, Honolulu, HI, USA

13 Global Wildlife Conservation (Now: Re:Wild), Austin, TX, USA

14 Australian Biological Resources Study, Department of Agriculture, Water and the Environment, Canberra, Australia

15 Natural History Museum Vienna, Vienna, Austria

16 Department of Evolutionary Biology, University of Vienna, Vienna, Austria

17 Department of Genetics, University of the Free State, Bloemfontein, South Africa

18 Manaaki Whenua-Landcare Research, Auckland, New Zealand

19 School of Biological Sciences, The University of Auckland, Auckland, New Zealand

20 Research Institute for the Environment and Livelihoods, Charles Darwin University, Darwin, Australia 


\section{Introduction}

It has been understood for many years that inadequate or ambiguous taxonomy and nomenclature for species can have negative impacts on conservation, medicine, and other fields ("taxonomy as destiny", May, 1990; see also Daugherty et al., 1990; Thomson, 1997; Frankham et al., 2012; Sangster \& Luksenburg, 2014; Gippoliti et al., 2018; Christenhusz, 2020; Lücking, 2020; Freemann \& Pennell, 2021). This happens in part because taxonomic names are often used as though they are stable hypotheses, when in fact taxonomies often have a degree of uncertainty and flux. Changes to species names or, often more importantly, changes to the concept of what a name means can have far-reaching implications for decision-making, regulation, and policy development. While taxonomic inflation (Isaac et al., 2004) or vandalism (Rhodin et al., 2015) can exacerbate these problems, even the normal growth of taxonomic knowledge can cause problems when not treated carefully. Problems can also occur when new taxonomic information fails to reach some users or when different users interpret taxonomic names, knowledge, or uncertainty in different ways. For some taxonomic groups, this can lead to multiple variants or competing taxonomies in different national jurisdictions or regions or even multiple competing global lists (Neate-Clegg et al., 2021). All of these problems may have real-world consequences for the conservation of species, regulation of trade, compliance with treaties, conduct of global business and agreements, and for the many sciences that rely on sound taxonomy for their research.

A key problem is that taxonomists necessarily divide the complex patterns of variation into simplified, discrete, and named units (taxa), which governments and the community then use to manage and understand biodiversity, one of the most complex systems we know. This has three consequences (Thiele et al., 2021): firstly, some diversity necessarily gets lost in the system; secondly, there are sometimes several to many possible taxonomies, none of which is entirely correct; and thirdly, many users are unaware of these nuances. A potential solution is to subdivide the taxa even further into evolutionarily significant units (Moritz, 1994) populations or groups of populations definable by measurably different allele frequencies-and use these as the basis for conservation etc. instead of species. However, dividing biodiversity into ESUs has all the same problems as dividing it into species, at a finer scale. Whatever unit is adopted, it is inevitable that there will be diversity in interpretation of boundaries, divergences of opinions, and differing interpretations of significance and uncertainty.

An important step towards managing these problems has been to develop consensus on which taxa to recognize. To that end, various groups, most notably the Catalogue of Life (Hobern et al., 2021), have spent more than two decades assembling the lists of species to create the basis of a single, agreed, global list of all the world's species. Building on that effort, Garnett et al. (2020) have proposed principles for governing such a list so that boundary disputes can be resolved in a way that gives users confidence that it truly represents a consensus on the most current and accurate taxonomic information available.

Critically, as also emphasized by Garnett et al. (2020), the problem with agreed taxonomic lists is rarely a problem with taxonomy itself. While adequate care and clarity in taxonomic research are essential for the effective application of its results, and while taxonomic research, as with all sciences, needs ongoing quality control through adequate peer review, it must remain a free and unfettered science. Rather than seek to constrain taxonomy, an appropriately governed global species list aims to rectify taxonomic and nomenclatural confusion, facilitate consensus among taxonomists, and provide a convenient reference for users.

In this paper, we make the case for a global effort to create and curate an appropriately governed global species list. Economic and social research required to understand the costs and benefits of species lists and their governance remains to be undertaken. We aim to demonstrate the realworld consequences that sometimes arise in the absence of consensus and accepted species lists, through a series of case studies relating to conservation, medicine, and other fields. We distinguish and illustrate five types of problem: lack of quality control, duplicated effort, conflicts of interest, lack of currency, and confusion in the scientific use of taxonomic information. These could have been (and in some cases have been) alleviated or prevented by a robust, reliable global species list. Most case studies concern vertebrates or plants, mainly because knowledge of these taxa, and their relevance to a wide user base, is relatively high (it will be a long time before examples can be drawn from most invertebrate groups).

\section{Issues related to list governance: Case studies}

\section{Vandalism and quality control}

In the last two decades, there has been an attempt by a small number of prolific workers to add $c .1800$ reptile taxa to the $c$. 10,000 species currently recognized. The taxonomic research on which many of these taxa are based has been of such poor quality and has used such ethically inappropriate approaches that it has been described as taxonomic vandalism (Kaiser et al., 2013; Wüster et al., 2021). Unfortunately, among all the sciences, taxonomy is almost uniquely prone to such vandalism. This is because all names considered 
published within the established rules of taxonomic nomenclature, available in zoology or valid in botany (e.g., the International Code of Zoological Nomenclature; ICZN, 1999; International Code of Nomenclature for algae, fungi, and plants, ICBN, 2018), are regarded as well-defined taxa and (potentially) acceptable, independent of their scientific merit. Meeting these requirements is relatively straightforward, and taxonomic vandals have become adept at meeting the letter of the code while often breaching its spirit. Two problems arise from taxonomic vandalism. The first is taxonomic: which of the taxa so erected are worthy of recognition? The second is nomenclatural, though not a code issue: what is the correct name to use when a taxon named through vandalism becomes widely accepted as a genuine taxon? A formally governed list of accepted taxa gives the taxonomic community a formal tool for dealing with such vandalism.

A good illustration of the efficacy of trusted species lists to address the problem of vandalism is provided by a recent and ongoing case involving herpetology. Two measures show promise for effectively foiling the attempt to reshape reptile taxonomy without the necessary scientific rigor. The first was a proposal by Kaiser et al. (2013) that the new names be boycotted by the profession. The second shows the value of accepted lists. Most reptile taxonomists do not adopt a new taxonomic hypothesis unless it has been included on a widely respected global list, the Reptile Database (Uetz et al., 2021). While this list is maintained by a few individuals, they are advised on contentious taxonomic issues by a 39-member Scientific Advisory Board and receive information and advice from 17 taxon and geographical editors as well as numerous other volunteers. The Reptile Database does not include new names unless and until they have become accepted by the broader herpetological taxonomic community. In this way, despite the vandal names being formally acceptable under the code, they are not formally accepted by the community of experts and the users of these resources. The Reptile Database, by providing a broad consensus list, has played a key role in limiting the damage caused by taxonomic vandals in herpetology.

The names of some reptiles have real-world consequences. For example, treatment of snakebite, one of the world's most neglected causes of death (Chippaux, 2017), relies on rapid and accurate identification of the snake to ensure that the correct antivenin is administered. The nomenclatural confusion caused by changing the generic names of potentially harmful snakes, for reasons that lack scientific merit, could lead directly to the deaths of snake bite victims. This happened when the antivenin for Indian saw-scaled viper (Echis spp.) was incorrectly supplied to West Africa, because the common and generic names were the same, resulting in a measurable increase in viper-related deaths in the region (Warrell, 2008).

\section{Duplicated effort and efficiency: Multiple bird lists and multiple users}

There are four major global bird lists in common usage (McLure et al., 2020; Neate-Clegg et al., 2021), and the fifth produced by North American government agencies (Integrated Taxonomic Information System, 2021), all of which have substantial differences in species recognized and species concepts adopted. What is less well-appreciated is that each list also has different, highly influential users. For example, two multilateral environmental agreements-the Convention on International Trade in Endangered Species of Wild Fauna and Flora (CITES) and the Convention on the Conservation of Migratory Species of Wild Animals (CMS) - aim to persuade governments to undertake actions to conserve and protect birds but use different taxonomies and different names for some species (e.g., white-necked cranes are Grus vipio under CITES but Antigone vipio under CMS). The CMS and the IUCN's Red List use the same list (based on Del Hoyo \& Collar, 2014, 2016), while CITES follows the older treatments (Dickinson, 2003, 2005) until it agrees to update its bird nomenclature standard. Birdwatchers around the world commonly use yet other lists (Gill et al., 2021; Schulenberg et al., 2021). None of these users consults the ITIS list (http://www.itis.gov), which contributes to the Catalogue of Life.

The result is confusion and duplication of effort, with each user group needing to engage independent taxonomic expertise to determine which taxonomic arrangement best suits their needs. The lack of an agreed global list also encourages the proliferation of multiple local and national lists, each reflecting the taxonomic philosophies of the individuals or committees who curate them. Data aggregators such as the Global Biodiversity Information Facility (GBIF) are often able to use synonymies to resolve conflicts between the lists, but communication and collaboration among jurisdictions are impeded by the existence and wide usage of multiple lists. While there are currently no detailed estimates of the cost of duplicated efforts or the work needed to resolve them, it seems highly likely that a single, well-governed list of the world's birds would be cheaper, more accurate, and more convenient than sustaining multiple lists.

Again, this case study illustrates how effective governance of species lists can resolve this problem. The International Ornithologist's Union has recently assembled a Working Group on Avian Checklists, whose primary purpose is to produce and maintain an open-access global checklist of birds that is intended to serve as the benchmark reference for all avian taxa. The task is well advanced because, for nearly three decades, ornithological taxonomy has been exceptionally well served by Avibase (https://avibase.bsceoc.org/avibase.jsp), a site maintained by a single individual. 
Avibase provides information on taxonomy, nomenclature, and synonymy for all of the $c$. 10,000 bird species and $c$. 22,000 subspecies, making it possible to understand the equivalence in concepts among the four major lists. The same rationale was behind the development of the World Register of Marine Species, an expert edited online database of all marine species in which nearly half the species names are considered synonyms (Appeltans et al., 2012, Costello et al., 2013).

\section{Conflicts of interest: Giraffes and orangutans}

Conservation priorities may change when new species are described. This is particularly the case when populations of high-profile, iconic species are split into two or more segregate species: populations previously regarded as part of a single widespread species may become species in their own right, thus increasing their apparent value and the case for their protection. Objectively, loss of a population (before the split) may be no less significant than the loss of the segregate species after the split, but the latter is usually deemed more significant (Mace, 2004). When populations are simultaneously reclassified as a species and listed as critically endangered, there is an added urgency as it implies the species has been neglected until recognized by taxonomists. However, such rapid acceptance of a taxonomic hypothesis carries dangers for the reputation of taxonomy-taxonomy cannot be a tool of conservation if it is to retain legitimacy among governments and the broader society (Garnett \& Christidis, 2007).

At times, there is an uncomfortably close association between taxonomy and conservation objectives. An example is the Tapanuli orangutan. In 2017, an orangutan population south of Lake Toba in Sumatra was newly described as a species, Pongo tapanuliensis (Nater et al., 2017) at about the same time as plans emerged for a large hydro-electric dam in the area. The new species was almost immediately accepted by the Primate Specialist Group of the IUCN and listed as Critically Endangered on the IUCN Red List (Nowak et al., 2017). Its plight was then used powerfully in advocacy and to generate conservation funds. However, designation of the Tapanuli orangutan as a species is controversial (see Stanton et al., 2019 and references therein), having been based on differences in the skull and teeth of a single male compared to 37 individuals from other orangutan populations, and dissimilarities in mitochondrial DNA (Nater et al., 2017). There is evidence of an exchange of male orangutans between the Tapanuli population and other populations (Nater et al., 2011), with only the more sedentary females being isolated. Mitochondrial DNA is inherited along female lineages and may diverge despite substantial interbreeding by dispersing males (Ghirotto et al., 2020). Because some co-authors of the paper describing the Tapanuli orangutan were members of the IUCN's Primate Specialist Group, which arbitrates the taxonomy used by the IUCN Red List, there is at least a perception of a conflict of interest in this decision. An adequately governed global list would overcome these apparent conflicts of interest by ensuring independent oversight and review of candidate taxonomies before acceptance onto the list.

A contrasting example concerns giraffes. The most recent taxonomic treatment of giraffes recognizes three extant species (Burgin et al., 2020; Petzold et al., 2020) divided into ten subspecies (Petzold et al., 2020). Other treatments recognize eight (Groves \& Grubb, 2011) or nine separate species (for a review see Bercovitch, 2020 and references therein). However, the IUCN currently recognizes a single extant species divided into nine subspecies, a treatment currently followed by more than $80 \%$ of academic publications (Bercovitch, 2020). Many populations of giraffes are highly imperiled and would be listed as critically endangered if considered species, potentially attracting more conservation funds. In this case, the relevant IUCN specialist group has opted for a conservative approach, in contrast to the primate specialist group.

Independent oversight and management of taxonomic lists, and a clear separation between decisions on taxonomy and conservation management, would ensure that standards are applied as consistently as possible, reducing the chances for anomalies such as these. This would ensure that users of mammal taxonomy can be confident that the taxonomy accepted for conservation management represents the consensus of a broad expert base, rather than reflecting the views of a small number of individuals, some of whom may have apparent or real competing interests.

\section{Nomenclatural and taxonomic currency: Silverfish, deathwatch beetles, and rust fungi}

Taxonomic knowledge is not stable and unchanging. Interpretations that at one point in time are widely accepted may be revised, and new insights are continuously added. Keeping the taxonomy of lists up-to-date is important for practical uses, such as biodiversity conservation, pest control, animal and plant health including human health, and import and export of biological materials. The practical uses of taxonomy for these purposes may be hampered by the use of outdated information. Moreover, taxonomic revisions often go hand in hand with the changes to names, and because names are the main keys for indexing and managing taxonomic information, the failure to adequately manage nomenclatural changes often has far-reaching consequences. Two common pest species demonstrate the difficulty that can be caused by even minor changes in the names of taxa.

Silverfish in the family Lepismatidae include cosmopolitan peridomestic pests such as the common silverfish Lepisma saccharina and Ctenolepisma longicaudata. A 
2018 ruling by the International Commission on Zoological Nomenclature (Opinion 2427; ICZN, 2018) determined that generic names based on "-lepisma," which had been treated as grammatically feminine, are neuter. Under the rules of nomenclature, this means that the endings of the species names need to be changed, i.e., for silverfish, to $L$. saccharinum and $C$. longicaudatum. The problem is that many organizations are unlikely to notice (or understand the reasons for) these changes: ICZN rulings take a long time to permeate the community, and they do so unevenly. This is likely to lead to different spellings being used simultaneously in different communities, leading in turn to ambiguous or incomplete results from computer-based searches. Although computer algorithms that accommodate variant spellings usually deal with common misspellings and the natural ways that people misspell, abstruse changes in taxonomic names (as from - $a$ to $-u m$ at the end of the name of a pest species) are unlikely to be corrected by general-purpose algorithms when searching for, e.g., pesticide approvals and compliance notices, leading to partial or incorrect results.

A similar example, for a different taxonomic reason, is the recent reclassification of globally important wood-boring pest beetles (including the death watch beetle) from the family Anobiidae to the family Ptinidae (Bell \& Phillips, 2012). Consequently, all biosecurity documentation that regulates, for example, against the importation of pest species belonging to the Anobiidae is now out of date. If an entomologist correctly identifies a beetle in a timber shipment as belonging in Ptinidae, biosecurity actions that are designed to protect against Anobiidae (e.g., EPPO, 2020; USDA, 2014) may not be triggered.

Occasionally, nomenclatural changes are substantial and wholesale within a taxonomic group, rather than occasional and ad hoc. An example comes from fungi, which have caused special nomenclatural problems due to their sometimes very complex life cycles. For example, many rust fungi have a sexual stage with a distinctive morphology on one host, and one or more asexual phases, usually with very different morphologies, found on other hosts. Because the life cycle stages could not be easily connected, for more than 150 years, different life cycle stages were given different valid names, even though they were the same species. The advent of molecular biology changed all this by allowing links between different stages to be proven genetically. Accordingly, the rules were changed to ensure that every fungal species is correctly assigned only one name. After some confusion (Redhead, 2010), working groups for all taxa affected have successfully implemented this change, resulting in wholesale nomenclatural changes in some of the most important groups of fungi for agriculture and biosecurity.

Given the rising costs incurred by invasive species (Diagne et al., 2021) standardization to a single source of taxonomic information could lead to very substantial savings by ensuring that the names of pest species are clear to all users. This has been partially achieved in the marine community through the establishment of a sub-database within WoRMS called WRiMS (World Register of introduced Marine Species) to manage introduced species information (Costello et al., 2021). Again, this has real-world consequences: multi-million-dollar mistakes are possible (or even likely) if the names of biosecurity-relevant species are not correctly controlled, and multi-million-dollar savings are possible if they are.

\section{Confusions in applying taxonomy in science}

In the previous sections, we have discussed how the lack of a well-governed species list has practical implications outside of science. However, taxonomy is also frequently used in a range of scientific fields. Just as with non-scientists, scientists in these fields may lack the expertise needed to arbitrate between different treatments, select the most up-to-date species list, and avoid nomenclatural confusion. This means that the same kinds of problems that affect non-scientific users also affect scientific users. For example, Isaac et al. (2004) and Faurby et al. (2016) have shown that variation in taxonomic opinions can have a strong effect on key analyses used in a range of ecological and evolutionary studies.

Critically, these problems are becoming more severe as science becomes increasingly reliant on digital data including biodiversity databases. Taxonomic names are key indexing terms for biodiversity data, and nomenclatural and taxonomic confusion are likely to impact the quality of the data that users retrieve from these databases. Multiple taxonomic treatments are often aggregated into one database, and different taxonomic sources are likely to be categorized together even if they were derived from different or competing taxonomies. A single, accepted, authoritative, global taxonomic list would provide a potential solution to all these problems.

\section{Discussion}

The benefits of an accepted list of the world's species and other taxa, readily accessible and used by workers in biodiversity conservation, management, legislation, medicine, and other fields, are best appreciated by understanding the detrimental impacts of the lack of such a list. These impacts stem from issues around coordination, trust, and currency.

A lack of coordination in developing global lists of species, both by producers and users, leads to duplicated effort and inefficiencies: list providers waste funding and effort by duplicating each other's work, and cooperation between users is compromised when they rely on different lists (Costello 
et al., 2013). A well-governed global list of the world's species could solve both these issues.

Better coordination would also build trust: a clear, pragmatic, broad-based, and well-coordinated effort to build a single global list of accepted species would increase trust by all parties that the list is well-founded and trustworthy. However, for taxonomy to be trusted, it must also be independent of its users. As Conix et al. (2021) outline, users have a role in setting some of the boundaries of taxonomy, where there are choices on principles to be adopted, but should have no role in the basic task of species delineation. These roles are sometimes confused, particularly when taxonomy is shaped by conservation imperatives or desires, even if the shaping is done for highly ethical reasons. Ultimately, confusion between taxonomy and conservation, and a lack of trust that the one is independent of the other, can damage the reputation of both, not least because it can lead to attacks from those with objectives other than conservation, or even legitimize pressure on taxonomists from those with development and other agendas.

Finally, a well-governed global list would resolve some of the problems discussed in this paper because it guarantees currency, within reason. Problems may arise when users rely on outdated taxonomic information or lists, but also when they rely too heavily on the very latest research before this has been tested, assessed, and accepted. These problems are particularly acute when multiple competing treatments are available. Keeping abreast of, and assessing, new taxonomic research needs to be devolved to specialists who can bring together information from their fields of knowledge transparently and equitably. Aggregating this collective knowledge into a single list means it can be rapidly disseminated to all users. If users trust a list, they will be disinclined to go to other taxonomic sources. A smoothly operating system would see the list updated at timely intervals, which would reduce legal loopholes for illegal trade, minimize quarantine breaches on the basis of anachronistic nomenclature, and allow rapid determination of the correct taxonomic names in a wide range of use cases.

We should note that the creation of a global list is not entirely without risk. While we think that huge benefits would arise from institutions and agreements like CITES, CMS, the IUCN, and government checklists underpinning legislation such as the US Endangered Species Act agreeing on a single list of species, we also acknowledge that there are some dangers inherent in doing so. Anything to do with primary science must be free from the imposition of preferred taxonomic lists; academic freedom is paramount in science. No author must ever be discouraged to publish taxonomic work that goes against an accepted list or taxonomic consensus of the day. Importantly, this implies that scientific journals and their editors must not impose a specific taxonomy on authors submitting taxonomic and nomenclatural manuscripts to them. For other scientific endeavors, it may be appropriate that journals do suggest conformity with global lists for clarity and it should be expected that authors use a current taxonomy as found in well-managed global lists or recent scholarly sources (Costello \& Wieczorek, 2014; Garnett et al., 2020; Kaiser et al., 2013). However, scientific journals must remain the playing field of taxonomic discussions and debates, and only further downstream in the process should various taxonomic suggestions be funneled into a single list to be used by the relevant stakeholders.

In many ways, the assembly of a global list and the development of processes to govern areas of disputation holds promise to complete the work started by Carl Linnaeus. Linnaeus not only developed the hierarchical system of classification still in use today, he also standardized scientific names and provided an extremely practical and useful means for communicating knowledge of biodiversity. He intended, in fact, to create and publish in his lifetime a single enumeration and classification of all living species on Earth. The task, of course, was vastly larger than he comprehended and has been carried on by generations of taxonomists since his death. Achieving Linnaeus' vision of a seamless and complete list of the world's known species will provide the means to communicate far more effectively than we can today about many aspects of biodiversity that have universal interest to biologists, conservationists, industry, medicine, and the general public.

Acknowledgements This paper is one of a series published by the IUBS Working Group on the Governance of Taxonomic Lists. We are grateful for the funding and support from the International Union of Biological Sciences and its Executive Officer Nathalie Fomproix, and the administration of the grant by Roanne Ramsey (Charles Darwin University). This paper has benefited greatly from discussions with all members of the Working Group, including those not listed as co-authors. S. Nikolaeva is supported by the Kazan Federal University Strategic Academic Leadership Program. Stijn Conix gratefully acknowledges the funding from the Research Council Flanders (FWO; Grant 3H200026).

Data availability Data sharing is not applicable to this article as no datasets were generated or analyzed during the current study.

\section{References}

Appeltans, W., Ahyong, S. T., Anderson, G., Angel, M. V., Artois, T., Bailly, N., et al. (2012). The magnitude of global marine species diversity. Current Biology 22, 1-14.

Bell, K. L., \& Philips, T. K. (2012). Molecular systematics and evolution of the Ptinidae (Coleoptera: Bostrichoidea) and related families. Zoological Journal of the Linnean Society, 165, 88-108. https://doi.org/10.1111/j.1096-3642.2011.00792.x

Bercovitch, F. B. (2020). Giraffe taxonomy, geographic distribution and conservation. African Journal of Ecology, 58, 50-158. https://doi. org/10.1111/aje.12741

Burgin, C. J., Wilson, D. E., Mittermeier, R. A., Rylands, A. B., Lacher, T. E., \& Sechrest, W. S. (2020). Illustrated checklist of 
the mammals of the world. In Vol. 2 Eulipotyphla to Carnivora, Lynx Edicions

Chippaux. J.-P. (2017). Snakebite envenomation turns again into a neglected tropical disease! Journal of Venomous Animals and Toxins including Tropical Diseases, 23, 38. https://doi.org/10.1186/ 2Fs40409-017-0127-6

Christenhusz, M. J. M. (2020). On species concepts, phylogenetics and the science of natural history-Three current issues facing taxonomy. Megataxa, 1(1), 67-72. https://doi.org/10.11646/ megataxa.1.1.14

Conix, S., Garnett, S. T., Thiele, K. R., Christidis, L., van Dijk, P. P., Bánki, O. S., Barik S. K., Buckeridge, J. S., Costello, M. J., Hobern, D., Kirk, P. M., Lien, A., Nikolaeva, S., Pyle, R. L., Thomson, S. A., Zhang, Z.-Q., Zachos, F. E. (2021). Towards a universal list of accepted species III. Independence and stakeholder inclusion. Organisms Diversity \& Evolution. https://doi. org/10.1007/s13127-021-00496-X

Costello, M. J., Bouchet, P., Boxshall, G., Fauchald, K., Gordon, D. P., Hoeksema, B. W., Poore, G. C. B., van Soest, R. W. M., Stöhr, S., Walter, T. C., Vanhoorne, B., Decock, W., \& Appeltans, W. (2013). Global coordination and standardisation in marine biodiversity through the World Register of Marine Species (WoRMS) and related databases. PLOS ONE, 8(1), e51629. https://doi.org/ 10.1371/journal.pone.0051629

Costello, M. J., \& Wieczorek, J. (2014). Best practice for biodiversity data management and publication. Biological Conservation, 173, 68-73.

Daugherty, C. H., Cree, A., Hay, J. M., \& Thompson, M. B. (1990). Neglected taxonomy and continuing extinctions of tuatara (Sphenodon). Nature, 347, 177-179.

Del Hoyo, J. \& Collar, N. J. (2014). Handbook of the Birds of the World and BirdLife International Illustrated Checklist of the Birds of the World. In Volume 1: Non-passerines. Lynx Edicions, Barcelona.

Del Hoyo, J. \& Collar, N. J. (2016). Handbook of the Birds of the World and BirdLife International Illustrated Checklist of the Birds of the World. In Volume 2: Passerines. Lynx Edicions, Barcelona.

Diagne, C., Leroy, B., Vaissière, A. C., Gozlan, R. E., Roiz, D., Jarić, I., Salles, J. M., Bradshaw, C. J., \& Courchamp, F. (2021). High and rising economic costs of biological invasions worldwide. Nature, 592, 571-576. https://doi.org/10.1038/s41586-021-03405-6

Dickinson, E. C. (Ed.). (2003). The Howard and Moore Complete Checklist of the Birds of the World. Revised and enlarged 3rd Edition. 1039 pp. London (Christopher Helm)

Dickinson, E. C. (2005). Corrigenda 4 (02.06.2005) to Howard \& Moore Edition 3 (2003)

EPPO. (2020). EPPO Technical Document No. 1081, EPPO Study on the risk of bark and ambrosia beetles associated with imported nonconiferous wood. EPPO Paris. https://www.eppo.int/RESOURCES/ eppo_publications

Faurby, S., Eiserhardt, W. L., \& Svenning, J.-C. (2016). Strong effects of variation in taxonomic opinion on diversification analyses. Methods in Ecology and Evolution, 7(1), 4-13. https://doi.org/10.1111/2041210X.12449

Freeman, B. G., \& Pennell, M. W. (2021). The latitudinal taxonomy gradient. Trends in Ecology and Evolution, 36(9), 778-786.

Frankham, R., Ballou, J. D., Dudash, M. R., Eldridge, M. D. B., Fenster, C. B., Lacy, R. C., Mendelson, J. R., III., Porton, I. J., Ralls, K., \& Ryder, O. A. (2012). Implications of different species concepts for conserving biodiversity. Biological Conservation, 153, 25-31.

Garnett, S. T., \& Christidis, L. (2007). Implications of changing species definitions for conservation purposes. Bird Conservation International, 17(3), 187-195.

Garnett, S. T., Christidis, L., Conix, S., Costello, M. J., Zachos, F. E., \& Ba'nki, O.S., Bao, Y., Barik, S. K., Buckeridge, J. S., Hobern, D. $\&$ Lien, A. . (2020). Principles for creating a single authoritative list of the world's species. PLoS Biology, 18(7), e3000736. https:// doi.org/10.1371/journal.pbio.3000736

Ghirotto, S., Vizzari, M. T., Tassi, F., Barbujani, G., \& Benazzo, A. (2020). Distinguishing among complex evolutionary models using unphased whole-genome data through random forest approximate Bayesian computation. Molecular Ecology Resources., 00, 1-15. https://doi.org/10.1111/1755-0998.13263

Gill, F., Donsker, D. \& Rasmussen, P. (Eds). (2021). IOC World Bird List (v11.1). https://doi.org/10.14344/IOC.ML.11.1

Gippoliti, S., Cotterill, F. P., Zinner, D., \& Groves, C. P. (2018). Impacts of taxonomic inertia for the conservation of African ungulate diversity: An overview. Biological Reviews, 93, 115-130.

Groves, C., \& Grubb, P. (2011). Ungulate taxonomy, The Johns Hopkins University Press.

Hobern, D., Barik, S. K., Christidis, L., Garnett, S. T., Kirk, P., Orrell, T. M., Pape, T., Pyle, R. L., Thiele, K. R., Zachos, F. E., Bánki, O. (2021). Towards a global list of accepted species VI: The Catalogue of Life Checklist. Organisms Diversity \& Evolution. https:// doi.org/10.1007/s13127-021-00516-w

ICZN. (1999). International Code of Zoological Nomenclature. Fourth edition. The International Trust for Zoological Nomenclature, London, UK.

International Commission on Zoological Nomenclature. (2018). Opinion 2427 (Case 3704) - Lepisma Linnaeus, 1758 (Insecta, Zygentoma, Lepismatidae): Direction 71 (1957) reversed. The Bulletin of Zoological Nomenclature, 75, 290-294. https://doi.org/10. 21805/bzn.v75.a064

Isaac, N. J., Mallet, J., \& Mace, G. M. (2004). Taxonomic inflation: Its influence on macroecology and conservation. Trends in Ecology and Evolution, 19, 464-469.

ITIS. (2021). the Integrated Taxonomic Information System https:// www.itis.gov/

Kaiser, H., Crother, B. I., Kelly, C. M. R., Luiselli, L., O'Shea, M., Ota, H., Passos, P., Schleip, W. D., \& Wüster, W. (2013). Best practices: In the $21^{\text {st }}$ century, taxonomic decisions in herpetology are acceptable only when supported by a body of evidence and published via peer-review. Herpetological Review, $44,8-23$.

Lücking, R. (2020). Three challenges to contemporaneous taxonomy from a licheno-mycological perspective. Megataxa, 1(1), 78-103. https://doi.org/10.11646/megataxa.1.1.16

Mace, G. M. (2004). The role of taxonomy in species conservation. Philosophical Transactions of the Royal Society B, 359, 711719. https://doi.org/10.1098/rstb.2003.14

May, R. M. (1990). Taxonomy as destiny. Nature, 347, 129-130. https://doi.org/10.1038/347129a0

McClure, C. J., Lepage, D., Dunn, L., Anderson, D. L., Schulwitz, S. E., Camacho, L., Robinson, B. W., Christidis, L., Schulenberg, T. S., Iliff, M. J., \& Rasmussen, P. C. (2020). Towards reconciliation of the four world bird lists: Hotspots of disagreement in taxonomy of raptors. Proceedings of the Royal Society B, 287(1929), 20200683.

Moritz, C. (1994). Defining evolutionarily significant units for conservation. Trends in Ecology and Evolution, 9, 373-375.

Nater, A., Nietlisbach, P., Arora, N., van Schaik, C. P., van Noordwijk, M. A., Willems, E. P., Singleton, I., Wich, S. A., Goossens, B., Warren, K. S., \& Verschoor, E. J. (2011). Sex-biased dispersal and volcanic activities shaped phylogeographic patterns of extant orangutans (genus: Pongo). Molecular Biology and Evolution, 28(8), 2275-2288. https://doi.org/10.1093/molbev/ msr042

Nater, A., Mattle-Greminger, M. P., Nurcahyo, A., Nowak, M. G., de Manuel, M., Desai, T., et al. (2017). Morphometric, behavioral, and genomic evidence for a new orangutan species. Current Biology, 27(2), 3487-3498. 
Neate-Clegg, M. H., Blount, J. D., \& Şekercioğlu, Ç. H. (2021). Ecological and biogeographical predictors of taxonomic discord across the world's birds. Global Ecology and Biogeography

Nowak, M. G., Rianti, P., Wich, S. A., Meijaard, E., \& Fredriksson, G. (2017). Pongo tapanuliensis. The IUCN Red List of Threatened Species 2017: e.T120588639A120588662. https://doi.org/ 10.2305/IUCN.UK.2017-3.RLTS.T120588639A120588662.en. Downloaded on 22 February 2021

Petzold, A., Magnant, A.-S., Edderai, D., Chardonnet, B., Rigoulet, J., Saint-Jalme, M., \& Hassanin, A. (2020). First insights into past biodiversity of giraffes based on mitochondrial sequences from museum specimens. European Journal of Taxonomy, 703, 1-33.

Redhead, S. A. (2010). Report on the Special Committee on the Nomenclature of Fungi with a Pleomorphic Life Cycle. Taxon 59(6): 1863-1866. https://doi.org/10.1002/tax.596017

Rhodin, A. G. J., Kaiser, H., van Dijk, P. P., Wüster, W., O'Shea, M., Archer, M., Auliya, M., Boitani, L., Bour, R., Clausnitzer, V., \& Contreras-MacBeath, T. (2015). Comment on Spracklandus Hoser, 2009 (Reptilia, Serpentes, ELAPIDAE): Request for confirmation of availability of the generic name and for the nomenclatural validation of the journal in which it was published. Bulletin of Zoological Nomenclature, 72(1), 65-78.

Rius, M., Ahyong, S., Costello, M. J., Galil, B. S., Gollasch, S., Hutchings, P., et al. (2021). World Register of Introduced Marine Species (WRiMS). Accessed at http://www.marinespecies.org/ introducedon 2021-10-06. https://doi.org/10.14284/347

Sangster, G., \& Luksenburg, J. A. (2014). Declining rates of species described per taxonomist: Slowdown of progress or a side-effect of improved quality in taxonomy? Systematic Biology, 64(1), 144-151.

Schulenberg, T. S., Iliff, M. I., Billerman, S. M., Sullivan. B. L., Wood, C. L., \& Fredericks, T. A. (2021). Clements Checklist. https:// www.birds.cornell.edu/clementschecklist/overview-august-2019/

Stanton, D. W., Frandsen, P., Waples, R. K., Heller, R., Russo, I. R. M., Orozco-terWengel, P. A., Pedersen, C.-E.T., Siegismund, H.
R., \& Bruford, M. W. (2019). More grist for the mill? Species delimitation in the genomic era and its implications for conservation. Conservation Genetics, 20(1), 101-113.

Thiele, K., Conix, S., Pyle, R. L., Barik, S. K., Christidis, L., Costello, M. J., van Dijk, P. P., Kirk, P., Lien, A., Thomson, S. A., Zachos, F. E., Zhang, Z.-Q., Garnett, S. T. (2021). Towards a global list of accepted species I. Why taxonomists sometimes disagree, and why this matters. Organisms Diversity \& Evolution. https://doi. org/10.1007/s13127-021-00495-y

Thomson, S. A. (1997). Management implications of poor alpha taxonomy. Australasian Wildlife Management Society Newsletter. March, 14-16.

Uetz, P., Freed, P. \& Hošek, J. (Eds.). (2021). The Reptile Database, http://www.reptile-database.org. Accessed 10/06/2021.

USDA - United States Department of Agriculture. (2014). Miscellaneous and processed products import manual regulating the importation of miscellaneous and processed products regulated by plant protection and quarantine. https://www.aphis.usda.gov/ import_export/plants/manuals/ports/downloads/miscellaneous.pdf

Warrell, D. A. (2008). Unscrupulous marketing of snake bite antivenoms in Africa and Papua New Guinea: Choosing the right product_- 'What's in a name?' Transactions of the Royal Society of Tropical Medicine \& Hygiene, 102(5), 397-399. https://doi.org/ 10.1016/j.trstmh.2007.12.005

Wüster, W., Thomson, S. A., O'Shea, M., \& Kaiser, H. (2021). Confronting taxonomic vandalism in biology: Conscientious community self-organisation can preserve nomenclatural stability. Biological Journal of the Linnean Society. blab009, https://doi. org/10.1093/biolinnean/blab009

Publisher's Note Springer Nature remains neutral with regard to jurisdictional claims in published maps and institutional affiliations. 